\title{
Topological Alterations of the Structural Brain Connectivity Network in Children with Juvenile Neuronal Ceroid Lipofuscinosis
}

\author{
(D)T. Roine, (D) U. Roine, (D) A. Tokola, (D) M.H. Balk, (D) M. Mannerkoski, DL. Åberg, (D)T. Lönnqvist, and (D). Autti
}

\begin{abstract}
BACKGROUND AND PURPOSE: We used diffusion MR imaging to investigate the structural brain connectivity networks in juvenile neuronal ceroid lipofuscinosis, a neurodegenerative lysosomal storage disease of childhood. Although changes in conventional MR imaging are typically not visually apparent in children aged $<10$ years, we previously found significant microstructural abnormalities by using diffusion MR imaging. Therefore, we hypothesized that the structural connectivity networks would also be affected in the disease.

MATERIALS AND METHODS: We acquired diffusion MR imaging data from 14 children with juvenile neuronal ceroid lipofuscinosis (mean \pm SD age, $9.6 \pm 3.4$ years; 10 boys) and 14 control subjects (mean \pm SD age, $11.2 \pm 2.3$ years; 7 boys). A follow-up MR imaging was performed for 12 of the patients (mean \pm SD age, $11.4 \pm 3.2$ years; 8 boys). We used graph theoretical analysis to investigate the global and local properties of the structural brain connectivity networks reconstructed with constrained spherical deconvolution-based whole-brain probabilistic tractography.
\end{abstract}

RESULTS: We found significantly increased characteristic path length $(P=.003)$ and decreased degree $(P=.003)$, which indicated decreased network integration and centrality in children with juvenile neuronal ceroid lipofuscinosis. The findings were similar for the follow-up MR imaging, and there were no significant differences between the two acquisitions of the patients. In addition, we found that the disease severity correlated negatively $(P<.007)$ with integration, segregation, centrality, and small-worldness of the networks. Moreover, we found significantly $(P<.0003)$ decreased local efficiency in the left supramarginal gyrus and temporal plane, and decreased strength in the right lingual gyrus.

CONCLUSIONS: We found significant global and local network alterations in juvenile neuronal ceroid lipofuscinosis that correlated with the disease severity and in areas related to the symptomatology.

ABBREVIATIONS: CLN3 = juvenile neuronal ceroid lipofuscinosis; CSD = constrained spherical deconvolution; LSD = lysosomal storage disease; UPDRS = Unified Parkinson's Disease Rating Scale

D iffusion-weighted MR imaging has enabled the in vivo investigation of white matter tracts in the brain. ${ }^{1}$ Different kinds of approaches have been applied, such as analyzing specific regions of interest or investigating the white matter tract skeleton of the brain. ${ }^{2}$ However, a large part of the white matter remains outside of these analyses. ${ }^{3,4}$ Recently, graph theoretical analysis

Received July 19, 2019; accepted after revision September 18.

From the Hospital District of Helsinki and Uusimaa Medical Imaging Center (T.R., U.R., A.T., M.H.B., T.A.), Radiology, Child Psychiatry (M.M.), Department of Psychiatry (L.A.), University of Helsinki and Helsinki University Hospital, Helsinki, Finland; Turku Brain and Mind Center (T.R.), University of Turku, Turku, Finland; Department of Neuroscience and Biomedical Engineering (T.R.), Aalto University School of Science, Espoo, Finland; and Department of Child Neurology (T.L.), Children's Hospital, University of Helsinki and Helsinki University, Helsinki, Finland.

This study was supported by a grant from Noah's Hope/Hope 4 Bridget, Thisbe and Noah Scott Foundation, and the Batten Disease Support and Research Association, Finnish Medical Foundation, Pehr Oscar Klingendahl Fund, Arvo and Lea Ylppö Foundation, Finnish Cultural Foundation, and Emil Aaltonen Foundation.

has been applied to investigate structural brain connectivity networks. ${ }^{5,6}$ In this approach, whole-brain tractography is first performed to reconstruct the white matter pathways of the brain, ${ }^{7}$ which are then used to weight connections between segmented gray matter areas. ${ }^{8}$ Graph theoretical metrics can then be used to investigate both global and local properties of these networks. ${ }^{9}$ This approach has been shown to be reproducible ${ }^{10}$ and has been used in several diseases, for example, schizophrenia, ${ }^{11}$ autism spectrum disorder, ${ }^{12}$ and Alzheimer disease. ${ }^{13}$

Please address correspondence to Timo Roine, PhD, Hospital District of Helsinki and Uusimaa Medical Imaging Center, Radiology, University of Helsinki and Helsinki University Hospital, PL 22 (Haartmaninkatu 4), FI-00014 Helsingin Yliopisto, Finland; e-mail: timo.roine@iki.f; @TimoRoine

\footnotetext{
- Indicates open access to non-subscribers at www.ajnr.org

三 Indicates article with supplemental on-line table.

Indicates article with supplemental on-line photos.

http://dx.doi.org/10.3174/ajnr.A6306
} 
Lysosomal storage diseases (LSDs) are often inherited in an autosomal recessive manner and are caused by mutations in genes encoding for enzymes involved in the degradation of macromolecules. ${ }^{14}$ This results in excessive storage of cellular material in lysosomes, which eventually leads to cell death and dysfunction of several organs. ${ }^{14}$ However, the CNS seems to be especially vulnerable to the storage of cellular material, and neurologic symptoms are common or, in some cases, even the only symptoms, in these disorders. ${ }^{14}$ The neuropathology of LSDs has been reviewed before ${ }^{14}$ and includes several mechanisms that lead to neurologic dysfunction, depending on the disease. However, in many of these diseases, the pathology is poorly understood.

The classification of LSDs also includes neuronal ceroid lipofuscinoses, ${ }^{14}$ a group of inherited, progressive, neurodegenerative disorders, in which autofluorescent ceroid lipopigments are accumulated in the lysosomes. Juvenile neuronal ceroid lipofuscinosis (CLN3) is caused by mutations in the CLN3 gene encoding a membrane protein, whose dysfunction leads to severe symptoms: progressive visual failure, which leads to blindness around the ages of 4 to 10 years ${ }^{15-17}$; deterioration in cognitive and motor functions; epileptic seizures; and neuropsychiatric symptoms. ${ }^{15}$ Also, the disease leads to death in the second or third decade of life. ${ }^{18}$ The exact mechanism of the disease is poorly understood, although several functions of the protein have been proposed: membrane fusion, vesicular transport, cytoskeletal linked function, lysosomal acidification, lysosomal arginine import, autophagy, apoptosis, and proteolipid modification. ${ }^{18}$

Previous MR imaging studies in patients with CLN3 reported cerebral and cerebellar atrophy, progressive hippocampal atrophy, alterations of the thalami, and decreased white matter volume in the corona radiata. ${ }^{19-21}$ In a postmortem study, higher MR imaging signal intensity of the periventricular white matter was reported, together with histologically observed severe periventricular loss of myelin and gliosis. ${ }^{22}$ We recently investigated the white matter microstructure of the brain in children with $\mathrm{CLN}^{23}$ and found significant global and widespread local differences by using tract-based spatial statistics ${ }^{2}$ and whole-brain tractography, ${ }^{7}$ even though conventional MR imaging is usually visually normal in patients aged $<10$ years. ${ }^{19}$

In this study, we analyzed the topological organization of the structural brain connectivity networks with graph theoretical methods. ${ }^{6}$ To our knowledge, these networks have not been investigated before in LSDs. We hypothesized that there would be 1) global topological alterations; and 2) local connectivity abnormalities in the structural brain connectivity networks in CLN3, and that they would be related to the severity of the symptoms. We used constrained spherical deconvolution (CSD)-based tractography ${ }^{7,24}$ instead of the more traditional $\mathrm{DTI}^{25}$ because the latter is unable to characterize crossing fibers, present in $60 \%-90 \%$ of the white matter. ${ }^{26}$ Most of the patients underwent follow-up MR imaging after 2 years, which allowed us to investigate longitudinal changes in the structural brain connectivity networks. Furthermore, we analyzed the correlations between the network properties and the scores from the Unified Parkinson's Disease Rating Scale (UPDRS) Part III Motor Examination. ${ }^{27}$
Table 1: Description of the symptoms of the patients with CLN3 during the first acquisition

\begin{tabular}{lccc}
\hline \multicolumn{1}{c}{ Symptoms } & None, $\boldsymbol{n}(\%)$ & Mild, $\boldsymbol{n}(\%)$ & Severe, $\boldsymbol{n}(\%)$ \\
\hline Visual impairment & $1(7)$ & $9(64)$ & $4(29)$ \\
Psychiatric symptoms & $9(64)$ & $4(29)$ & $1(7)$ \\
Epilepsy & $9(64)$ & $3(21)$ & $2(14)$ \\
Intellectual disability & $9(64)$ & $4(29)$ & $1(7)$ \\
Motor impairment & $9(64)$ & $5(36)$ & $0(0)$ \\
\hline
\end{tabular}

\section{MATERIALS AND METHODS Participants}

We acquired diffusion-weighted MR imaging data from 14 patients with CLN3 (age, mean \pm SD $9.3 \pm 3.1$ years; 10 boys) and 14 age-matched control subjects (age, mean \pm SD $11.3 \pm$ 2.3 years; 7 boys). The control subjects were healthy volunteers recruited through the personnel mailing list of the Helsinki University Hospital. They were attending conventional elementary school education and did not have regular medication, brain diseases, or long-term diagnoses. One of the control subjects had to be excluded due to image artifacts. A follow-up MR imaging was performed for 12 of the patients (age mean \pm SD $11.2 \pm$ 3.1 years; 8 boys). The differences in age were not statistically significant between the patients and the controls. The motor performance of the patients was clinically evaluated with UPDRS Part III before the first (score, mean \pm SD $5.5 \pm 8.6$ [range, 0$23]$ ) and second (score, mean \pm SD $7.6 \pm 13.8$ [range, 0-38]) MR imaging acquisition.

The patients were diagnosed based on their clinical symptoms, including the deterioration of vision and typical ophthalmologic findings. The symptoms of each patient are described in more detail in Table 1 . The diagnoses were confirmed by a DNA analysis. ${ }^{23}$ Symptomatic medication typical to the disease was in use. The ethics committee for Gynaecology and Obstetrics, Pediatrics and Psychiatry of the Hospital District of Helsinki and Uusimaa approved the research protocol, and a guardian of all the participants signed a written informed consent form before the study.

\section{Data Acquisition}

The MR imaging data were acquired with an (Philips Medical Systems, Best, Netherlands) Achieva 3T scanner (Phillips Healthcare, Best, the Netherlands) and an 8-channel head coil by using a $2 \mathrm{~mm} \times 2 \mathrm{~mm} \times 2 \mathrm{~mm}$ voxel size and 32 gradient orientations with a diffusion weighting of $1000 \mathrm{~s} / \mathrm{mm}^{2}$. In addition, 1 non-DWI was acquired. The field of view was $224 \mathrm{~mm} \times$ $224 \mathrm{~mm} \times 160 \mathrm{~mm}$, and 80 axial slices were acquired. Echo time was $59.5 \mathrm{~ms}$, and repetition time was 10.809 seconds. T1weighted anatomic $3 \mathrm{D}$ images were acquired with a resolution of $1 \mathrm{~mm} \times 1 \mathrm{~mm} \times 1 \mathrm{~mm}$. The field of view was $256 \mathrm{~mm} \times$ $256 \mathrm{~mm} \times 170 \mathrm{~mm}$, repetition time was $8.3 \mathrm{~ms}$, echo time was $3.8 \mathrm{~ms}$, and the flip angle was $8^{\circ}$. T2WIs were acquired, with a resolution of $0.5 \mathrm{~mm} \times 0.5 \mathrm{~mm} \times 4.4 \mathrm{~mm}$ and for 8 of the 12 patients in the second acquisition, fluid-attenuated inversion recovery images were acquired, with a resolution of $0.4 \mathrm{~mm} \times 0.4 \mathrm{~mm} \times 4.4 \mathrm{~mm}$.

\section{Reconstruction of the Structural Brain Connectivity Networks}

We first corrected the diffusion-weighted data for subject motion $^{28}$ and eddy current-induced distortions in ExploreDTI 


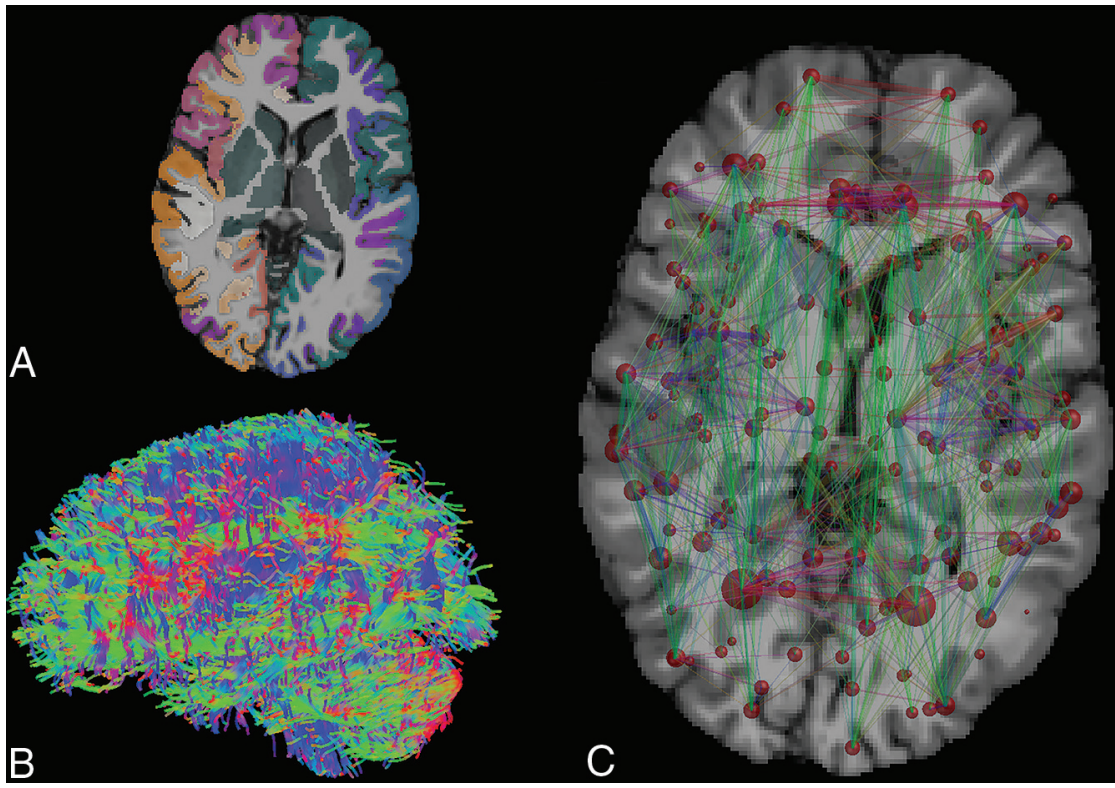

FIG 1. Reconstruction of the structural brain connectivity networks. A, Cortical and subcortical parcellation of the $T \mathrm{WI}$ results in 164 gray matter regions. $B$, Whole-brain probabilistic streamlines tractography based on the corrected DWI can be used to reconstruct structural connectivity pathways of the brain. C, The structural brain connectivity network, in which the nodes represent the gray matter areas and the edges are weighted by the number of streamlines that connect the nodes. The size of the nodes corresponds to the volume of the gray matter area. The width of the edges corresponds to the number of streamlines, and the color of the edges corresponds to the direction of the connection (red: left-right, green: anterior-posterior, blue: superior-inferior).
Civier et $\mathrm{al}^{33}$ we did not apply a threshold based on the number of streamlines to the networks. The graph theoretical analyses were performed in Matlab (MathWorks, Natick, Massachusetts) by using the Brain Connectivity Toolbox. ${ }^{9}$ In the global analysis, we investigated degree, strength, clustering coefficient, ${ }^{34}$ characteristic path length, ${ }^{35}$ global efficiency, ${ }^{36}$ betweenness centrality, ${ }^{37}$ and small-worldness. ${ }^{35}$ Local node-level analyses were performed for strength, local efficiency, and betweenness centrality. The measures are presented in more detail in the On-line Table.

\section{Statistical Analyses}

Statistical analyses were performed with the general linear model in SPSS Statistics version 25 (IBM, Armonk, New York) by using age and sex as covariates. The results were corrected for multiple comparisons with the Bonferroni correction. The partial correlations with the UPDRS Part III scores were calculated by using age and sex as covariates. (version 4.8.6; http://exploredti.com/). ${ }^{29}$ Because no reverse phase-encoding data were available, we used nonlinear registration with cubic splines to the T1-weighted data to correct for the echo-planar imaging distortions. ${ }^{30}$ We then estimated fiber orientation distributions with $\mathrm{CSD}^{24}$ by using up to fourth-order spherical harmonics. We performed probabilistic CSD-based tractography ${ }^{7}$ in ExploreDTI ${ }^{29}$ with a seed point resolution of $1.0 \mathrm{~mm} \times 1.0 \mathrm{~mm} \times 1.0 \mathrm{~mm}$ within the brain mask, step size of $1 \mathrm{~mm}$, fiber orientation distribution threshold of 0.1 , angle threshold of $45^{\circ}$, and fiber length range of 50 to $500 \mathrm{~mm}$. Cortical and subcortical gray matter parcellation of the T1WI was performed in FreeSurfer ${ }^{8}$ (http://surfer.nmr.mgh.harvard.edu) by using the Destrieux atlas. ${ }^{31}$ Also, the 2 ends of each reconstructed streamline were assigned to gray matter areas based on the parcellation, including the cerebellum, as described in Fig 1. In the structural brain connectivity networks, the nodes represent the gray matter areas, and the edges represent the reconstructed streamlines between the nodes, which resulted in a $164 \times 164$ connectivity matrix weighted by the number of streamlines. The networks were visualized in MRtrix3 (http://neuro.debian.net/ pkgs/mrtrix.html), ${ }^{32}$ and the whole-brain tractography was performed (Fig 1B) in ExploreDTI. ${ }^{29}$

\section{Graph Theoretical Analysis of the Brain Network Properties}

We investigated global and local properties of the structural brain connectivity networks weighted by the number of streamlines by using graph theoretical analysis. ${ }^{6,9}$ Based on a study in 2019 by

\section{RESULTS}

\section{Global Graph Theoretical Properties}

We found global differences in the topological organization of the structural brain connectivity networks be-tween the patients with CLN3 and the healthy control subjects. The characteristic path length was significantly increased $(P=.003)$ and the degree was significantly decreased in patients with CLN3 $(P=.003)$, as shown in Table 2. In addition, clustering coefficient, global efficiency, small-worldness, and strength were decreased in patients with CLN3 $(P<.05)$ but did not endure the Bonferroni correction for multiple comparisons.

The results were similar for the first and the second acquisitions of the patients compared with the control subjects, as shown in Table 2. However, small-worldness was not decreased $(P>.05)$ during the second acquisition of the patients with CLN3 compared with the control subjects, and betweenness centrality was increased $(P<.05)$. No significant differences were found in any of the global network properties between the 2 acquisitions of the patients with CLN3 on the group level or by using a pair-wise $t$ test $(P>.05)$. The global results are further visualized in On-line Figure 1.

We found significant correlations between several global network properties and the UPDRS Part III scores in patients with CLN3, including the data from both the first and second acquisitions, as shown in Fig 2. Clustering coefficient, global efficiency, small-worldness, and strength correlated negatively, and characteristic path length correlated positively with the UPDRS Part III 
Table 2: Global differences in the network properties between the patients with CLN3 and the control subjects, with age and sex used as covariates

\begin{tabular}{lccccc}
\hline & \multicolumn{2}{c}{ CLN3 $^{\mathrm{a}}$} & & & \multicolumn{2}{c}{} \\
\cline { 2 - 4 } \multicolumn{1}{c}{ Network Property } & $\begin{array}{c}\text { First } \\
\text { Acquisition }\end{array}$ & $\begin{array}{c}\text { Second } \\
\text { Acquisition }\end{array}$ & $\begin{array}{c}\text { Control } \\
\text { Subjects }\end{array}$ & $\begin{array}{c}\text { CLN3 First Acquisition } \\
\text { vs. Control Subjects }\end{array}$ & $\begin{array}{c}\text { CLN3 Second Acquisition } \\
\text { vs. Control Subjects }\end{array}$ \\
\hline Betweenness centrality & $288 \pm 22$ & $294 \pm 17$ & $278 \pm 11$ & .084 & .008 \\
Characteristic path length & $0.118 \pm 0.062$ & $0.130 \pm 0.073$ & $0.074 \pm 0.014$ & $.003^{\mathrm{b}}$ & $.003^{\mathrm{b}}$ \\
Clustering coefficient & $5.27 \pm 1.57$ & $5.32 \pm 2.12$ & $6.45 \pm 0.77$ & .011 & .017 \\
Degree & $25.9 \pm 4.6$ & $25.3 \pm 5.0$ & $29.5 \pm 1.79$ & $.003^{\mathrm{b}}$ & $.002^{\mathrm{b}}$ \\
Global efficiency & $22.6 \pm 8.6$ & $22.8 \pm 11.6$ & $28.5 \pm 4.5$ & .014 & .030 \\
Small-worldness & $5.03 \pm 0.85$ & $5.24 \pm 1.19$ & $5.78 \pm 0.80$ & .009 & .126 \\
Strength & $511 \pm 191$ & $506 \pm 255$ & $645 \pm 105$ & .012 & .020 \\
\hline
\end{tabular}

${ }^{\text {a }}$ Data are mean \pm standard deviation

${ }^{\mathrm{b}}$ Indicates significant differences after the Bonferroni correction for multiple comparisons.
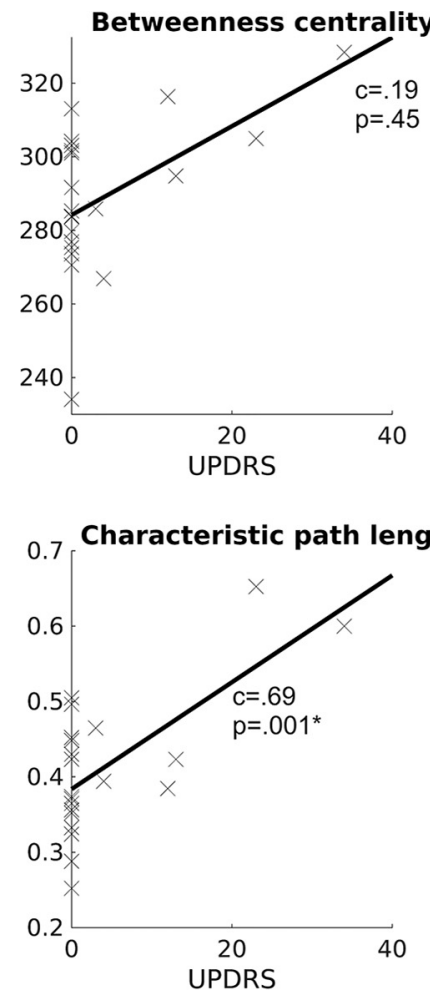
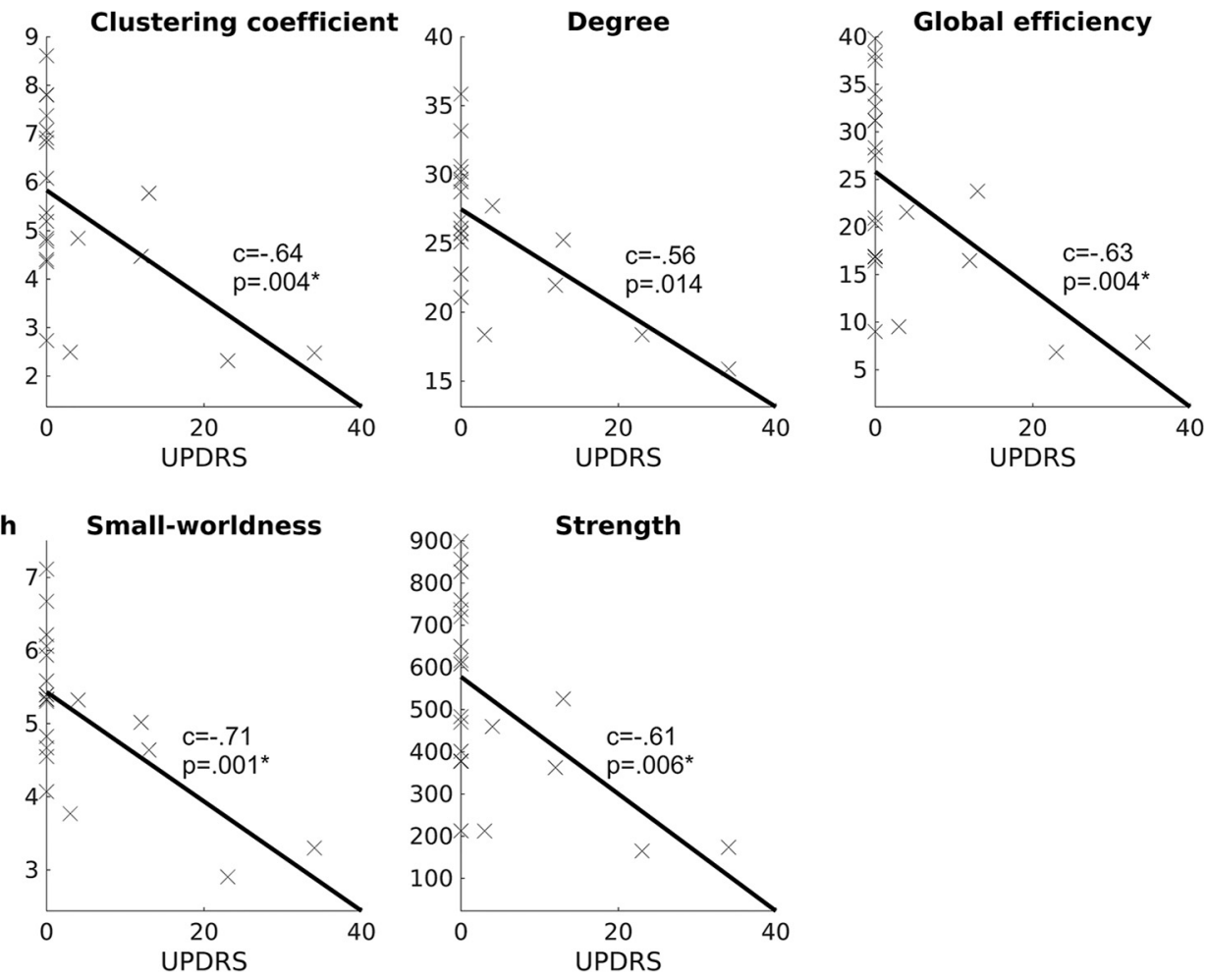

FIG 2. Scatterplots and the fitted lines, describing the correlation between the global network properties and UPDRS Part III: motor examination scores. Statistically significant (Bonferroni corrected) correlation coefficients (c) are marked with an asterisk.

scores. The correlations were similar for the first and second acquisitions separately but did not endure the Bonferroni correction for multiple comparisons.

\section{Local Graph Theoretical Properties}

We investigated 3 local network properties: betweenness centrality, local efficiency, and strength. In the first acquisition of the patients with CLN3 compared with the control subjects, we found increased betweenness centrality in 1 region $(P<.01)$, decreased local efficiency in 27 regions $(P<.01)$, and decreased strength in 9 regions $(P<.01)$ in CLN3. These results are presented in more detail in the On-line Figure 2 and On-line Figure 3. However, none of these results endured the Bonferroni correction for multiple comparisons.

In the second acquisition of the patients with CLN3 compared with the control subjects, we found increased betweenness centrality in the left thalamus $(P=.002)$ and in the left middle frontal gyrus $(P=.004)$, decreased local efficiency in 48 regions $(P<.01)$, and decreased strength in 7 regions $(P<.01)$, as shown in On-line Figure 3. These results are illustrated in Fig 3. Of these results, the decreased local efficiency of the left supramarginal gyrus in the inferior parietal lobe and left temporal plane of the superior temporal gyrus, and the decreased strength of the right lingual gyrus in the medial occipitotemporal gyrus remained significant after the Bonferroni correction for multiple comparisons $(P<.0003)$. These results are emphasized with red circles in Fig 3.

Between the first and the second acquisitions of the patients with CLN3, we found differences $(P<.01)$ in 2 regions: increased betweenness centrality in the orbital part of the right inferior frontal gyrus; and increased strength in the area, including the right lingual gyrus and the right medial occipito- 


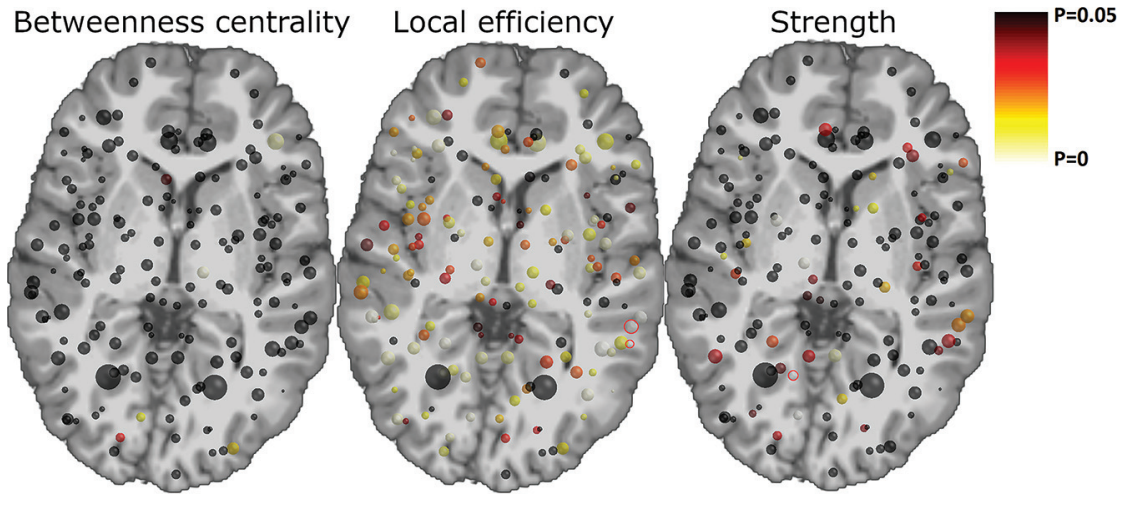

FIG 3. Local differences in betweenness centrality, local efficiency, and strength between the second acquisition of the patients with CLN3 and the control subjects. The size of the nodes illustrates the volume of the gray matter region, and the color indicates the statistical significance of the differences $(P$ values). Significant differences $(P<.0003)$ after a Bonferroni correction for multiple comparisons are highlighted with red circles. Local efficiency was decreased in the left supramarginal gyrus and the left temporal plane, and strength was decreased in the right lingual gyrus. impairment increases. Strength correlated negatively with the UPDRS Part III scores, but the correlation of degree was not significant after the correction for multiple comparisons.

We investigated 3 local network properties: betweenness centrality, local efficiency, and strength. Local efficiency and strength were decreased in $20 \%-30 \%$ of the nodes in children with CLN3. However, only 3 nodes remained significant after the Bonferroni correction for multiple comparisons, and thus, other results should be interpreted with caution. The 3 significant differences were the decreased local efficiency in the left supramarginal gyrus and the left temporal plane, temporal sulcus. These results were not significant after the Bonferroni correction.

\section{DISCUSSION}

In this study, we compared both global and local structural brain network properties between children with CLN3 and agematched controls. Twelve of 14 patients underwent a follow-up MR imaging after 2 years, which allowed us to investigate longitudinal changes. Moreover, we investigated whether the global network properties correlated with motor impairment.

The comparison of the global graph theoretical properties between the children with CLN3 and the control subjects revealed a significantly increased characteristic path length and decreased degree in CLN3. Characteristic path length ${ }^{35}$ is a measure of integration of the network, and it describes how easily the different nodes, in this case, gray matter areas, can communicate with each other. ${ }^{9}$ An increased characteristic path length suggests that the integration of the structural brain networks in children with CLN3 is decreased, which may indicate that the networks in CLN3 are more lattice, with a lower number of interconnecting links. ${ }^{6}$ The decreased degree indicates decreased centrality of the networks in CLN3.

However, there were no significant differences in the global or local network properties between the 2 acquisitions of the patients with CLN3, similar to our previous results with concern to the white matter microstructure. ${ }^{23}$ This suggests that neither the microstructural nor the connectivity properties change rapidly at this age and that the alterations are present already before the age of 10 years.

Moreover, we investigated the correlation between the global network measures and UPDRS Part III scores. The characteristic path length was positively correlated and global efficiency was negatively correlated with UPDRS Part III scores, which suggests an increase in motor impairment, with a decrease of the integration of structural brain networks. The small-worldness and clustering coefficient correlated negatively with the scores, which indicates that the segregation decreases when the motor and decreased strength in the right lingual gyrus in patients with CLN3, which indicate that the structural connectivity of these areas would be impaired in CLN3.

The temporal plane forms a major part of the Wernicke area, and is thought to be involved in early phonological and nonword auditory processing. ${ }^{38,39}$ Lesions near or including the area might lead to auditory discrimination and speech comprehension deficits, and the area is assumed to be involved in Wernicke aphasia. ${ }^{38}$ The left temporal plane is typically larger in healthy subjects, and reduced asymmetry has been linked to schizophrenia and dyslexia. ${ }^{38}$ Some of the patients with CLN3 experience hallucinations, and some might also produce jargon, which is also a symptom of Wernicke aphasia. However, in our experience, it is more common for the patients with CLN3 to have problems in speech production than the content of the speech.

The supramarginal gyrus belongs to the inferior parietal lobe, together with the angular gyrus. ${ }^{40,41}$ Based on a classic neurobiological model of language, the inferior parietal lobe is involved in the recognition of visual word forms, ${ }^{42}$ which are then linked to auditory word forms in the Wernicke area, and motor patterns in the Broca area. ${ }^{40}$ Increased activation of the supramarginal gyrus has been reported when focusing on the sound of the words in contrast to their meaning. ${ }^{43}$ The supramarginal gyrus is connected to auditory association areas in the posterior supratemporal plane and posterior inferior frontal gyrus, ${ }^{44}$ both of which are involved in phonological processing. ${ }^{45}$ Difficulties related to phonological word decisions are typically related to damage in the left hemisphere ${ }^{46}$ and might lead to conduction aphasia ${ }^{44,47}$ or Wernicke aphasia. ${ }^{48}$ In CLN3, the speech difficulties increase as the disease progresses and include, for instance, difficulties in starting to speak and festinating stuttering. ${ }^{49}$

The lingual gyrus, a region in the occipital lobe, has been linked to vision, especially related to processing of letters, ${ }^{50-52}$ encoding of complex images, ${ }^{53}$ impairment of visual memories, ${ }^{54}$ and logical order of events. ${ }^{55}$ The lingual gyrus has also been related to semantic processing during a task with repeating stimuli during a variety of aphasia tests in subjects with aphasia. ${ }^{56}$ In 
addition, possible links to the hippocampal regions (related to recollection of facts) ${ }^{57}$ and the amygdala (related to high-emotion words and images) have been reported. ${ }^{58}$ Also, the occipitotemporal region is involved in perception of colors ${ }^{59,60}$ and faces, ${ }^{61,62}$ and especially the right lingual gyrus has been related to prosopagnosia $^{63,64}$ and to topographagnosia, ${ }^{65}$ the inability to recognize faces and landmarks, respectively. In CLN3, the first symptom is usually an impairment in vision that leads rapidly to blindness. Decreased strength in the right lingual gyrus indicates that patients with CLN3 have fewer connections from the lingual gyrus to other nodes than do the control subjects.

Previous MR imaging findings indicate that there are thalamic alterations in LSDs. ${ }^{66}$ In CLN3, decreased gray matter volume in the dorsomedial part of the thalami has been reported. ${ }^{67} \mathrm{We}$ found decreased local efficiency and strength in the right thalamus and increased betweenness centrality in the left thalamus. However, the results that concern the thalami did not endure correction for multiple comparisons.

Limitations of this study include a relatively small sample size, which is common in rare diseases, for example, CLN3. In addition, the acquisition was suboptimal for CSD-based tractography because the diffusion weighting and the number of gradient orientations and non-DWIs were relatively low, ${ }^{68}$ and reverse-phase encoding data were not available. However, fiber crossings can be reliably identified with $\mathrm{CSD}^{69}$ In the future, multi-shell diffusion-weighted MR imaging acquisition may be used to enable more advanced models, such as neurite orientation dispersion and attenuation imaging, ${ }^{70}$ and improve tractography within the gray matter. $^{71,72}$

\section{CONCLUSIONS}

We found increased characteristic path length and decreased degree, which indicate decreased global integration and centrality of the structural brain connectivity networks in CLN3. Local analyses revealed differences in the left supramarginal gyrus, the left temporal plane, and the right lingual gyrus. In addition, although not significant after correction for multiple comparisons, the changes in the right thalamus are interesting because thalamic alteration have been reported consistently in LSDs. No significant differences were observed between the 2 acquisitions of the patients in the network properties. Our previous study, together with the current study, indicate that, in patients with CLN3, the microstructural white matter abnormalities and changes in the structural brain network properties are present already before the age of 10 years and do not progress rapidly in the prepubertal stage.

\section{ACKNOWLEDGMENT}

We acknowledge the computational resources provided by the Aalto Science-IT project.

Disclosures: T. Roine-RELATED: Grant: Noah's Hope/Hope 4 Bridget, Thisbe and Noah Scott Foundation, Batten Disease Support and Research Association,* Comments: Money was paid to University of Helsinki, of which salary for 3 months was paid to me; Other: Emil Aaltonen Foundation, Finnish Cultural Foundation, Comments: Personal research grants (a total of 24 months). U. Roine-RELATED: Grant: Noah's Hope/Hope 4 Bridget, Thisbe and Noah Scott Foundation, and the Batten Disease Support and Research Association,*
Comments: Money paid to University of Helsinki, and of these funds, salary for 5 months was paid to me; Support for Travel to Meetings for the Study or Other Purposes: Arvo and Lea Ylppö Foundation, Comments: Travel grant to attend Annual Meeting of the Organization for Human Brain Mapping 2018 conference; Other: Finnish Medical Foundation, Pehr Oscar Klingendahl Fund, and Arvo and Lea Ylppö Foundation, Comments: Personal research grants partially granted for this research project. L. Åberg-UNRELATED: Employment: Normal clinical work at the clinic for the intellectually impaired, City of Helsinki. T. Autti-RELATED: Grant: Batten Disease Support and Research Association, Comments: Grant $\$ 60,000$. ${ }^{*}$ Money paid to the institution.

\section{REFERENCES}

1. Tournier JD, Mori S, Leemans A. Diffusion tensor imaging and beyond. Magn Reson Med 2011;65:1532-56 CrossRef Medline

2. Smith SM, Jenkinson M, Johansen-Berg H. Tract-based spatial statistics: voxelwise analysis of multi-subject diffusion data. Neuroimage 2006;31:1487-505 CrossRef Medline

3. Jones DK, Knösche TR, Turner R. White matter integrity, fiber count, and other fallacies: The do's and don'ts of diffusion MRI. Neuroimage 2013;73:239-54 CrossRef Medline

4. Bach M, Laun FB, Leemans A, et al. Methodological considerations on tract-based spatial statistics (TBSS). Neuroimage 2014;100:35869 CrossRef Medline

5. Hagmann P, Cammoun L, Gigandet X, et al. Mapping the structural core of human cerebral cortex. PLoS Biol 2008;6:e159 CrossRef

6. Bullmore ET, Sporns O. Complex brain networks: graph theoretical analysis of structural and functional systems. Nat Rev Neurosci 2009;10:186-98 CrossRef Medline

7. Jeurissen B, Leemans A, Jones DK, et al. Probabilistic fiber tracking using the residual bootstrap with constrained spherical deconvolution. Hum Brain Mapp 2011;32:461-79 CrossRef Medline

8. Fischl B, van der Kouwe A, Destrieux C, et al. Automatically parcellating the human cerebral cortex. Cereb Cortex 2004;14:11-22 CrossRef Medline

9. Rubinov M, Sporns O. Complex network measures of brain connectivity: uses and interpretations. Neuroimage 2010;52:1059-69 CrossRef Medline

10. Roine T, Jeurissen B, Perrone D, et al. Reproducibility and intercorrelation of graph theoretical measures in structural brain connectivity networks. Med Image Anal 2019;52:56-67 CrossRef Medline

11. van den Heuvel MP, Mandl RCW, Stam CJ, et al. Aberrant frontal and temporal complex network structure in schizophrenia: A graph theoretical analysis. J Neurosci 2010;30:15915-26 CrossRef Medline

12. Roine U, Roine T, Salmi J, et al. Abnormal wiring of the connectome in adults with high-functioning autism spectrum disorder. Mol Autism 2015;6:65. CrossRef Medline

13. Lo $\mathrm{CY}$, Wang $\mathrm{PN}$, Chou $\mathrm{KH}$, et al. Diffusion tensor tractography reveals abnormal topological organization in structural cortical networks in Alzheimer's disease. J Neurosci 2010;30:16876-85 CrossRef Medline

14. Boustany RM. Lysosomal storage diseases-the horizon expands. Nat Rev Neurol 2013;9:583 CrossRef Medline

15. Santavuori P, Lauronen L, Kirveskari K, et al. Neuronal ceroid lipofuscinoses in childhood. Suppl Clin Neurophysiol 2000;53:443-51 CrossRef Medline

16. Collins J, Holder GE, Herbert H, et al. Batten disease: features to facilitate early diagnosis. Br J Ophthalmol 2006;90:1119-24 CrossRef Medline

17. Spalton DJ, Taylor DS, Sanders MD. Batten's disease: an ophthalmological assessment of 26 patients. Br J Ophthalmol 1980;64:72632 CrossRef Medline

18. Jalanko A, Braulke T. Neuronal ceroid lipofuscinoses. Biochim Biophys Acta 2009;1793:697-709 CrossRef Medline

19. Autti T, Raininko R, Vanhanen SL. MRI of neuronal ceroid lipofuscinosis: I. Cranial MRI of 30 patients with juvenile neuronal ceroid lipofuscinosis. Neuroradiology 1996;38:476-82 CrossRef Medline 
20. Tokola AM, Salli EK, Åberg LE, et al. Hippocampal volumes in juvenile neuronal ceroid lipofuscinosis: a longitudinal magnetic resonance imaging study. Pediatr Neurol 2014;50:158-63 CrossRef Medline

21. Autti T, Joensuu R, Åberg L. Decreased T2 signal in the thalami may be a sign of lysosomal storage disease. Neuroradiology 2007;49: 571-78 CrossRef Medline

22. Autti T, Raininko R, Santavuori P, et al. MRI of neuronal ceroid lipofuscinosis. II. Postmortem MRI and histopathological study of the brain in $\mathbf{1 6}$ cases of neuronal ceroid lipofuscinosis of juvenile or late infantile type. Neuroradiology 1997;39:371-77 CrossRef Medline

23. Roine U, Roine TJ, Hakkarainen A, et al. Global and widespread local white matter abnormalities in juvenile neuronal ceroid lipofuscinosis. AJNR Am J Neuroradiol 2018;39:1349-54 CrossRef Medline

24. Tournier J-D, Calamante F, Connelly A. Robust determination of the fibre orientation distribution in diffusion MRI: non-negativity constrained super-resolved spherical deconvolution. Neuroimage 2007;35:1459-72 CrossRef Medline

25. Basser PJ, Mattiello J, LeBihan D. MR diffusion tensor spectroscopy and imaging. Biophys J 1994;66:259-67 CrossRef Medline

26. Jeurissen $B$, Leemans A, Tournier JD, et al. Investigating the prevalence of complex fiber configurations in white matter tissue with diffusion magnetic resonance imaging. Hum Brain Mapp 2013; 34:2747-66 CrossRef Medline

27. Movement Disorder Society Task Force on Rating Scales for Parkinson's Disease. The Unified Parkinson's disease rating scale (UPDRS): status and recommendations. Mov Disord 2003;18:73850 CrossRef Medline

28. Leemans A, Jones DK. The B-matrix must be rotated when correcting for subject motion in DTI data. Magn Reson Med 2009;61:133649 CrossRef Medline

29. Leemans A, Jeurissen B, Sijbers J, et al. ExploreDTI: a graphical toolbox for processing, analyzing, and visualizing diffusion MR data. Proc 17th Sci Meet Int Soc Magn Reson Med 2009;17:3537

30. Irfanoglu MO, Walker L, Sarlls J, et al. Effects of image distortions originating from susceptibility variations and concomitant fields on diffusion MRI tractography results. Neuroimage 2012;61:275-88 CrossRef Medline

31. Destrieux C, Fischl B, Dale A, et al. Automatic parcellation of human cortical gyri and sulci using standard anatomical nomenclature. Neuroimage 2010;53:1-15 CrossRef Medline

32. Tournier JD, Calamante F, Connelly A. MRtrix: Diffusion tractography in crossing fiber regions. Int J Imaging Syst Technol 2012;22:5366 CrossRef

33. Civier O, Smith RE, Yeh C, et al. Is removal of weak connections necessary for graph-theoretical analysis of dense weighted structural connectomes from diffusion MRI? Neuroimage 2019;194:6881 CrossRef Medline

34. Saramäki J, Kivelä M, Onnela JP, et al. Generalizations of the clustering coefficient to weighted complex networks. Phys Rev E Stat Nonlinear Soft Matter Phys 2007;75(Pt 2):027105

35. Watts DJ, Strogatz SH. Collective dynamics of "small-world" networks. Nature 1998;393:440-42 CrossRef Medline

36. Latora V, Marchiori M. Efficient behavior of small-world networks. Phys Rev Lett 2001;87:198701 CrossRef Medline

37. Freeman LC. Centrality in social networks conceptual clarification. Soc Netw 1978;1:215-39 CrossRef

38. Shapleske J, Rossell SL, Woodruff PW, et al. The planum temporale: a systematic, quantitative review of its structural, functional and clinical significance. Brain Res Brain Res Rev 1999;29:26-49 CrossRef Medline

39. Binder JR, Frost JA, Hammeke TA, et al. Function of the left planum temporale in auditory and linguistic processing. Brain 1996;119: 1239-47 CrossRef Medline

40. Stoeckel C, Gough PM, Watkins KE, et al. Supramarginal gyrus involvement in visual word recognition. Cortex 2009;45:1091-96 CrossRef Medline
41. Rushworth MF, Behrens TE, Johansen-Berg H. Connection patterns distinguish 3 regions of human parietal cortex. Cereb Cortex 2006; 16:1418-30 CrossRef Medline

42. Déjerine J. Sur un cas de cécité verbale avec agraphie suivi d'autopsie [On a case of verbal blindness with agraphia, followed by autopsy]. Mémoires Société Biol 1891;3:197-201.

43. Devlin JT, Matthews PM, Rushworth M. Semantic processing in the left inferior prefrontal cortex: a combined functional magnetic resonance imaging and transcranial magnetic stimulation study. $J$ Cogn Neurosci 2003;15:71-84 CrossRef Medline

44. Catani M, Jones DK, Ffytche DH. Perisylvian language networks of the human brain. Ann Neurol 2005;57:8-16 CrossRef Medline

45. Poldrack RA, Wagner AD, Prull MW, et al. Functional specialization for semantic and phonological processing in the left inferior prefrontal cortex 1. Neuroimage 1999;35:15-35 CrossRef

46. Hartwigsen G, Baumgaertner A, Price CJ, et al. Phonological decisions require both the left and right supramarginal gyri. Proc Natl Acad Sci U S A 2010;107:16494-99 CrossRef Medline

47. Arnett PA, Swanson SJ, Hammeke TA. Conduction aphasia in multiple sclerosis: a case report with MRI findings. Neurology 1996; 47:576-78 CrossRef Medline

48. Kertesz A, Lau WK, Polk M. The structural determinants of recovery in Wernicke's aphasia. Brain Lang 1993;44:153-64 CrossRef Medline

49. Mole SE, Williams RE. Neuronal ceroid-lipofuscinoses. In: Adam M, Ardinger H, Pagon R, et al. eds. GeneReviews. Seattle: University of Washington, 2001

50. Patterson K, Brown WD, Wise R, et al. The cortical localization of the lexicons: positron emission tomography evidence. Brain 1992;115:1769-82 CrossRef Medline

51. Price CJ, Wise RJS, Watson JDG, et al. Brain activity during reading. The effects of exposure duration and task. Brain 1994;117(Pt 6):1255-69 CrossRef Medline

52. Bookheimer SY, Zeffiro TA, Blaxton T, et al. Regional cerebral blood flow during object naming and word reading. Hum Brain Mapp 1995;3:93-106 CrossRef

53. Machielsen WC, Rombouts SA, Barkhof F, et al. FMRI of visual encoding: reproducibility of activation. Hum Brain Mapp 2000;9:156-64 CrossRef Medline

54. Bogousslavsky J, Miklossy J, Deruaz J-P, et al. Lingual and fusiform gyri in visual processing: a clinico-pathologic study of superior altitudinal hemianopia. J Neurol Neurosurg Psychiatry 1987;50:60714 CrossRef Medline

55. Brunet E, Sarfati Y, Hardy-Baylé MC, et al. A PET investigation of the attribution of intentions with a nonverbal task. Neuroimage 2000;11:157-66 CrossRef Medline

56. Heath S, McMahon KL, Nickels L, et al. Neural mechanisms underlying the facilitation of naming in aphasia using a semantic task: an fMRI study. BMC Neurosci 2012;13:98 CrossRef Medline

57. Cho S, Metcalfe AWS, Young CB, et al. Hippocampal - prefrontal engagement and dynamic causal interactions in the maturation of children's fact retrieval. J Cogn Neurosci 2012;24:1849-66 CrossRef Medline

58. Isenberg N, Silbersweig D, Engelien A, et al. Linguistic threat activates the human amygdala. Proc Natl Acad Sci U S A 1999;96: 10456-59 CrossRef Medline

59. Damasio A, Yamada T, Damasio H, et al. Central achromatopsia: behavioral, anatomic, and physiologic aspects. Neurology 1980;30: 1064. CrossRef Medline

60. Meadows JC. Disturbed perception of colours associated with localized cerebral lesions. Brain 1974;97:615-32 CrossRef Medline

61. Kanwisher N. Domain specificity in face perception. Nat Neurosci 2000;3:759-63 CrossRef Medline

62. Meadows JC. The anatomical basis of prosopagnosia. J Neurol Neurosurg Psychiatry 1974;37:489-501 CrossRef Medline

63. Damasio AR, Damasio H, Van Hoesen GW. Prosopagnosia: anatomic basis and behavioral mechanisms. Neurology 1982;32:331 CrossRef Medline 
64. Barton JJS, Press DZ, Keenan JP, et al. Lesions of the fusiform face area impair perception of facial configuration in prosopagnosia. Neurology 2002;58:71-78 CrossRef Medline

65. Takahashi N, Kawamura M. Pure topographical disorientation the anatomical basis of landmark agnosia. Cortex 2002;38:717-25 CrossRef Medline

66. Tokola AM, Åberg LE, Autti TH. Brain MRI findings in aspartylglucosaminuria. J Neuroradiol 2015;42:345-57 CrossRef Medline

67. Autti T, Hämäläinen J, Åberg L, et al. Thalami and corona radiata in juvenile NCL (CLN3): A voxel-based morphometric study. Eur J Neurol 2007;14:447-50 CrossRef Medline

68. Tournier JD, Calamante F, Connelly A. Determination of the appropriate $b$ value and number of gradient directions for high-angular- resolution diffusion-weighted imaging. NMR Biomed 2013;26:177586 CrossRef Medline

69. Farquharson S, Tournier JD, Calamante F, et al. White matter fiber tractography: why we need to move beyond DTI. J Neurosurg 2013;118:1367-77 CrossRef Medline

70. Zhang H, Schneider T, Wheeler-Kingshott CA, et al. NODDI: practical in vivo neurite orientation dispersion and density imaging of the human brain. Neuroimage 2012;61:1000-16 CrossRef Medline

71. Jeurissen B, Tournier JD, Dhollander T, et al. Multi-tissue constrained spherical deconvolution for improved analysis of multishell diffusion MRI data. Neuroimage 2014;103:411-26 CrossRef Medline

72. Roine T, Jeurissen B, Perrone D, et al. Informed constrained spherical deconvolution (iCSD.). Med Image Anal 2015;24:269-81 